\title{
Editorial Teaching and learning
}

\author{
David Cottrell
}

The publication of Tomorrow's Doctors (General Medical Council (GMC), 1993) started a revolution in medical education - the effects of which will make themselves felt for many years to come. For decades, changes in medical knowledge and practice had been acknowledged in the undergraduate curriculum by squeezing more lectures and practicals into an increasingly overcrowded timetable. The GMC called a halt to this, pointing out that even if we could cram all the current knowledge into the heads of medical students in five years, most of it would be out of date within two to three years of qualifying. Instead, it was suggested that medical schools should seek to reduce the amount of information taught to students. Core knowledge, skills and attitudes essential for clinical practice have to be identified (the GMC identified certain core themes, but shied away from setting a national curriculum for medicine), and taught in only two-thirds of the five-year undergraduate course. According to the GMC, the other third of the undergraduate course should be spent on 'special study modules', periods in which students can exercise choice and where opportunities are provided for in-depth study. Special study modules also provide opportunities for learning generic, transferable skills such as communication, literature-searching, problemsolving, project work, basic research methodology, report-writing and others.

The GMC has been criticised, particularly by those who are concerned that today's medical students may qualify knowing less, despite the fact that there is more for them to know. However, the GMC places much emphasis on self-directed learning and expects students to acquire the skills necessary to find things out for themselves, and to become lifelong learners. The intention is that doctors will acquire the habit of finding out early and, by qualification, will be self-motivated and selfdirected, able to access and utilise many forms of information and equipped for continually adding to, and updating, their own knowledge and skills.
These changes in the undergraduate years have been followed by recommendations for the preregistration house officer (PRHO) year (GMC, 1997). The GMC sees the PRHO year as a continuation of undergraduate training, during which educational supervisors (consultants) will provide in-service training for the newly qualified doctors. Those responsible for PRHO learning are expected to have received training in this role and to sign written learning agreements. Postgraduate deans will have to organise formal assessments of PRHOs and their placements, at the end of each six-month period in the PRHO year.

Detailed recommendations for senior house officer training cannot be long in coming, but major changes in registrar/senior registrar training have already arrived with the advent of the specialist registrar (Department of Health, 1993). Structured training programmes with clear learning objectives have been established, and more detailed and rigorous assessment of doctors is now carried out at this stage of training.

In all of these changes there are implicit, and sometimes explicit, assumptions about the nature of teaching and learning. Learning experiences must be planned and coordinated from the moment the student starts at medical school. Self-directed learning and problem-solving are highly prized skills. There is an emphasis on the acquisition, and assessment, of skills and attitudes as well as knowledge. Limited, but achievable, objectives can be set at one stage of training because there will be opportunities to acquire more specialist knowledge and skills at a later stage. Even the specialist registrar, in proud possession of a Certificate of Completion of Specialist Training, is not to be seen as someone whose training has finished, but someone who will continue to update his or her knowledge and skills after appointment to a consultant post.

In the old days when much medical learning was supposed to take place by 'osmosis' while on an apprenticeship, there was little discussion of 
teaching and learning - it was just something that happened. It is difficult to see how modern consultants will be able to fulfill their educational commitments to undergraduates, postgraduates and to themselves without a fairly thorough grounding in educational theory and practice. Many medical schools are now insisting that staff who teach their students must have had some formal training in how to teach. Some Royal Colleges are now recommending that consultants not be allowed to supervise junior doctors unless they have attended a teaching skills course. Other Colleges are proposing that a set percentage of Continuing Professional Development credits (perhaps 10\%) should be earned by attending teacher training events.

Some articles about teaching, in specific subject areas, have already been published in this journal. Starting in this issue is a series of articles about teaching and learning which address a range of generic teaching and learning topics all of which should be of relevance to all psychiatrists, irrespective of sub-specialisation. The series starts with an article about supervision, still the cornerstone of most clinical learning. In future months there will be articles on managing postgraduate education and on specific teaching skills such as small group teaching, problem-based learning, lectures and seminars and computer-assisted learning. We will look at learning objectives and at innovative methods of assessment. The series will conclude with an article about the contribution psychiatry can make to the general undergraduate training of tomorrow's doctors.

These articles can only provide a theoretical knowledge base regarding teaching practice. In addition, all doctors need to ensure that they have a range of teaching skills and can facilitate learning in others as well as in themselves. Today's doctors will need to be competent teachers if they are to help produce tomorrow's doctors. They may also need to become better learners if they want to keep up with tomorrow's doctors.

\section{References}

Department of Health (1993) Hospital Doctors: Training for the Future. The Report of the Working Group on Specialist Medical Training (The Calman Report). London: Department of Health.

General Medical Council (1993) Tomorrow's Doctors. Recommendations on Undergraduate Medical Education. London: GMC.

- (1997) The New Doctor. Recommendations on General Clinical Training. London: GMC.

\title{
Forthcoming from Gaskell
}

\section{Camberwell Assessment of Need}

\author{
Mike Slade, Graham Thornicroft, Linda Loftus, \\ Michael Phelan \& Til Wykes
}

The Camberwell Assessment of Need (CAN) is a tried and tested approach to assessing the needs of the severely mentally ill. Rigorously developed by staff at the Section of Community Psychiatry (PRiSM), Institute of Psychiatry, it records both staff and patient assessments. Three versions are included, all designed to be photocopied. The full clinical research versions give a comprehensive assessment, and a short (one page) version (CANSAS) is suitable for routine clinical use. Also included are materials and instructions for a half-day CAN training workshop.

The CAN is suitable for use in primary care settings, specialist mental health teams and social services. It will be of particular interest to care managers and mental health staff who wish to meet the legal requirement that the severely mentally ill receive a comprehensive needs assessment.

Spring 1999, £45.00, 144pp, Ringbound pack incl. photocopiable material, ISBN 1901242250

Book Sales, Royal College of Psychiatrists, 17 Belgrave Square, London SW1X 8PG. Telephone +44 (0)171 2352351 ext. 146, fax +44(0)171 2451231. Credit card orders can be taken over the telephone.

See the latest information on College publications on the Internet at:

http://www.rcpsych.ac.uk 